\title{
ANALISIS ROCKMASS RATING DI TEPI PANTAI SAMABE, PULAU BALI
}

\author{
Abdi Suprayitno ${ }^{1}$, A.M.Miftahul Huda ${ }^{2}$, dan Mohammad Muntaha ${ }^{3}$ \\ ${ }^{1}$ Program Studi Teknik Perminyakan, Sekolah Tinggi Teknologi Migas, Balikpapan \\ ${ }^{2}$ Program Studi Teknik Instrumentasi Elektronika Migas, Sekolah Tinggi Teknologi Migas, Balikpapan \\ ${ }^{3}$ Departemen Teknik Sipil, Fakultas Teknik Sipil Lingkungan dan Kebumian, Institut Teknologi Sepuluh Nopember, \\ Surabaya \\ e-mail : ${ }^{1}$ abdi@sttmigas.ac.id / abdi.sttmigas@gmail.com \\ 2*mustafid13@gmail.com / miftahul@sttmigas.ac.id
}

\begin{abstract}
Abstrak. Stabilitas batuan dibutuhkan untuk segala infrastruktur yang dibangun di area yang memiliki kemiringan tertentu terutama di daerah lereng terjal. Penelitian ini dilakukan pada lereng bukit di tepi Pantai Samabe dibagian bawah bangunan hotel. Identifikasi kerentanan lereng terhadap longsor dilakukan menggunakan analisa Rock Mass Rating. Penyelidikan dilakukan pada 4 (empat) lokasi pengamatan berdasarkan temuan longsor minor dibagian pinggir tebing. Hasil dari analisa tersebut, lereng ini masuk dalam kategori lereng cukup baik sampai baik. Penanganan yang dibutuhkan berupa pemasangan rock bolts dan wire mesh kemudian dibungkus dengan pengecoran semen.
\end{abstract}

Kata Kunci: pantai Samabe; rock mass rating; stabilitas batuan

Abstract. Stability is needed for all infra-structure built in certain slope areas on steep slopes. The research was carried out on the hillside on the edge of Samabe Beach which is located below the hotel. Identification of slope stability assessment was held using Rock Mass Rating Analysis. This assessment was conducted in 4 (four) observation area based on minor landslide found at this slope. The results are some parts of this slope in fair rock category and the others are in good category. For slope handling forwards are rock bolts and wire mesh installation with cement grouting covering material.

Keywords: Samabe beach; rock mass rating; rock stability

\section{PENDAHULUAN}

Stabilitas batuan merupakan aspek penting yang harus dipenuhi dalam proses perencanaan maupun desain pembangunan sampai pemeliharaan (Syaeful dan Kamajati, 2017). Berbagai penelitian mendukung pernyataan tersebut sebagaimana yang telah dilakukan oleh Prengki dan Heriyadi (2018) untuk menguji ketidakstabilan lubang bukaan melalui identifikasi karakteristik batuan. Selain itu, dengan menggunakan nilai-nilai massa batuan dapat pula diperkirakan sudut kemiringan lereng pada pertambangan batu bara dalam rangka menjamin pemenuhan faktor keamanan lereng, dan penanganan secara cepat terhadap kondisi lereng (Zakaria dkk., 2012). Faktor-faktor keamanan lereng dapat dihitung berdasarkan sifat fisik, mekanik, dan geometri dari lahan (Pangular, 1985).
Kerawanan suatu lereng terhadap longsor disebabkan oleh faktor eksternal dan internal, namun pada umumnya untuk berberapa kasus lebih banyak disebabkan oleh faktor internal lereng tersebut (Zakaria, 2011). Dilaporkan oleh Rajagukguk dkk (2014) tingkat kejenuhan dapat menurunkan kekuatan tanah sehingga longsor dapat terjadi.

Pentingnya studi terkait kestabilan lereng bukan hanya untuk pertambangan, maupun infrastruktur jalan, tetapi penting juga untuk lahan pemukiman atau pun bangunan gedung tinggi. Untuk itu, dalam upaya mengetahui dan memitigasi bencana longsor di Hotel Samabe yang terletak di Tepi Pantai Samabe, Bali dilakukan analisa Rock Mass Rating (RMR).

\section{METODOLOGI}




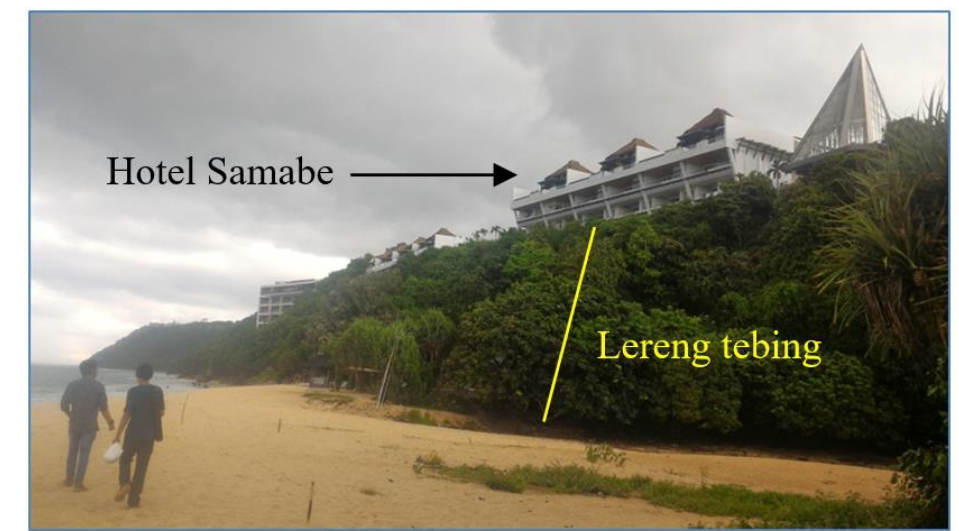

Gambar 1. Lokasi Hotel Samabe Di Atas Tebing (Sumber Pribadi, 2017)

Hotel Samabe terletak pada tepi pantai sebelah selatan Pulau Bali, berupa lereng dengan ketinggian antara 70 sampai $80 \mathrm{~m}$ dari permukaan laut. Dengan kemiringan lereng bervariasi antara 60 sampai 80 derajat. Lereng merupakan bentang alam kars dari batuan batugamping yang belum mengalami pelapukan lanjut sehingga hanya membentuk gua di tepi pantainya. Potensi adanya runtuhan batuan cukup besar dimana retakanretakan banyak ditemukan ditubuh batugamping.

Secara geologi batuan di lokasi survei termasuk ditemukan struktur geologi dengan dimensi yang cukup besar berarah dip $20^{\circ} / \mathrm{N} 308^{\circ}$ E dan $77^{\circ} / \mathrm{N} 75^{\circ}$ E. Analisis arah struktur geologi memberikan potensi adanya resiko wedge di lereng tersebut dimana arahnya saling berpotongan dengan arah lereng dari lokasi survei yaitu $\mathrm{N} 165^{\circ} \mathrm{E} / 45^{\circ}$.

Data diambil dari sifat fisik batuan dan karakteristik retakan pada batuan tersebut. Sifat fisik batuan meliputi jenis batuan, warna, tingkat pelapukan dan kekuatan batuan. Sedangkan parameter retakan meliputi $R Q D$, dimensi retakan

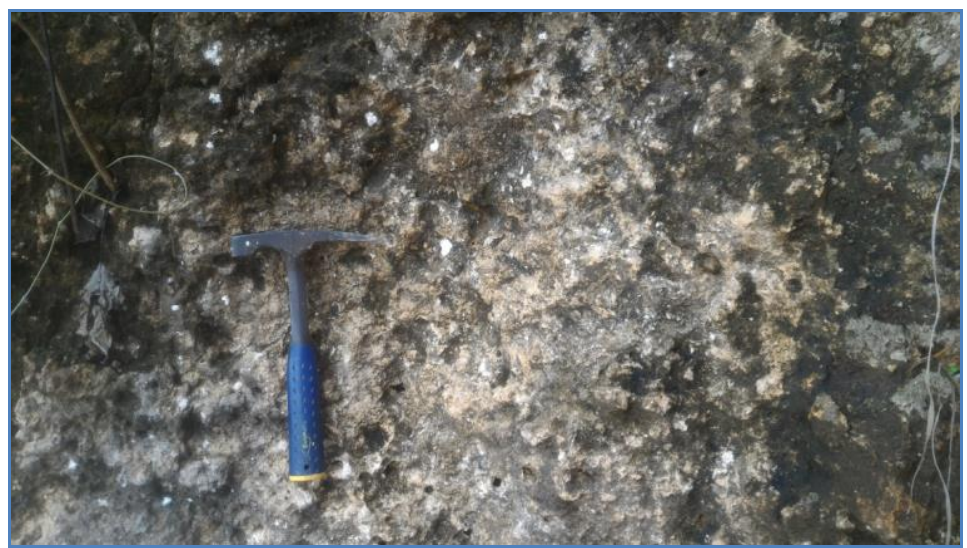

Gambar 2. Kondisi Batugamping Terumbu di lokasi penelitian (Sumber Pribadi, 2017)

ke dalam Formasi Selatan yang berisi Batugamping Terumbu, Napal sebagian berlapis dan berfosil. Batuan ini diperkirakan berumur Miosen Akhir sampai Pliosen. Batugamping merupakan batuan yang memiliki tingkat kekuatan medium sampai tinggi. Hal ini disebabkan proses terbentuknya secara alami oleh sebagian besar unsur kalsium yang diambil dari airlaut dan diproses langsung oleh bakteri mikro di laut dangkal. Sebagian tempat dan bukaan serta pengaruh airtanah pada retakan.

Pengambilan data dilakukan di 4 stasiun pengamatan. Lokasi longsoran di sebelah barat lereng, gua kecil, gua besar dan lokasi rencana elevator dibawah gereja. Tabel 1 dan 2 merupakan deskripsi detail dari data yang diambil per stasiun. Selain itu dimasukkan pula skor dari parameter yang masuk kedalam penilaian Rock Mass Rating (Bieniawski, 1989). 


\section{HASIL DAN PEMBAHASAN}

Tabel dibawah ini merupakan hasil deskripsi batuan terhadap tebing dibawah hotel. Ditentukan 4 area stasiun pengamatan untuk penentuan nilai RMR berdasarkan temuan longsor minor di bagian tebingnya.

Tabel 1. Deskripsi Kondisi Keteknikan Stasiun Pengamatan 1 dan 2

\begin{tabular}{|c|c|c|c|c|}
\hline Parameter & Stasiun 1 & Skor & Stasiun 2 & Skor \\
\hline $\begin{array}{l}\text { Jenis } \\
\text { Batuan }\end{array}$ & $\begin{array}{c}\text { Batugamping } \\
\text { Pasiran }\end{array}$ & & Batugamping & \\
\hline $\begin{array}{l}\text { Warna } \\
\text { Batuan }\end{array}$ & $\begin{array}{c}\text { Coklat Muda - } \\
\text { Coklat Tua }\end{array}$ & & $\begin{array}{c}\text { Putih - Coklat } \\
\text { Muda }\end{array}$ & \\
\hline $\begin{array}{c}\text { Tingkat } \\
\text { Pelapukan }\end{array}$ & $\begin{array}{l}\text { Rendah - } \\
\text { Sedang }\end{array}$ & & $\begin{array}{l}\text { Segar - } \\
\text { Rendah }\end{array}$ & \\
\hline \multirow[t]{2}{*}{$\begin{array}{l}\text { Kondisi } \\
\text { Lereng }\end{array}$} & $\begin{array}{l}\text { Sebagian } \\
\text { tertutup } \\
\text { vegetasi }\end{array}$ & & $\begin{array}{c}\text { Berada } \\
\text { didalam gua }\end{array}$ & \\
\hline & $\begin{array}{c}\text { Dijumpai } \\
\text { longsoran } \\
\text { minor } \\
\text { disebelah barat }\end{array}$ & & $\begin{array}{c}\text { Sebagian } \\
\text { besar dilapisi } \\
\text { oleh lumut }\end{array}$ & \\
\hline $\begin{array}{c}\text { Kekuatan } \\
\text { Batuan }\end{array}$ & $\begin{array}{l}\text { Rendah - } \\
\text { Sedang }\end{array}$ & 4 & Sedang & 7 \\
\hline RQD & $75 \%$ & 17 & $64 \%$ & 13 \\
\hline $\begin{array}{c}\text { Spasi Antar } \\
\text { Retakan }\end{array}$ & $60-200 \mathrm{~cm}$ & 15 & $6-10 \mathrm{~cm}$ & 8 \\
\hline $\begin{array}{l}\text { Panjang } \\
\text { Retakan }\end{array}$ & $7-10 m$ & 2 & $-12 m$ & 2 \\
\hline $\begin{array}{c}\text { Lebar } \\
\text { Retakan }\end{array}$ & $1-10 \mathrm{~cm}$ & 0 & $1-10 \mathrm{~cm}$ & 0 \\
\hline $\begin{array}{c}\text { Kekasaran } \\
\text { Bidang } \\
\text { Retakan }\end{array}$ & Kasar & 5 & Kasar & 5 \\
\hline $\begin{array}{c}\text { Pengisi } \\
\text { Bidang } \\
\text { Retakan }\end{array}$ & Lumut & 2 & Lumut & 2 \\
\hline $\begin{array}{c}\text { Pelapukan } \\
\text { Pada } \\
\text { Retakan }\end{array}$ & Sedang & 3 & $\begin{array}{l}\text { Segar- } \\
\text { Rendah }\end{array}$ & 5 \\
\hline Airtanah & $\begin{array}{c}\text { Dijumpai } \\
\text { tetesan dari } \\
\text { retakan }\end{array}$ & 4 & $\begin{array}{c}\text { Dinding } \\
\text { lembab dan } \\
\text { basah }\end{array}$ & 7 \\
\hline Total Nilai & Fair Rock & 52 & Fair Rock & 49 \\
\hline
\end{tabular}

Tabel 2. Deskripsi Kondisi Keteknikan Stasiun Pengamatan 3 dan 4

\begin{tabular}{|c|c|c|c|c|}
\hline Parameter & Stasiun 3 & Skor & Stasiun 4 & Skor \\
\hline $\begin{array}{c}\text { Jenis } \\
\text { Batuan }\end{array}$ & Batugamping & & Batugamping & \\
\hline Warna & Putih - Coklat & & Putih - Coklat & \\
\hline Batuan & Muda & & Muda & \\
\hline Tingkat & Segar - & & Segar - & \\
\hline Pelapukan & Rendah & & Rendah & \\
\hline Kondisi & Berada & & Hasil dari & \\
\hline
\end{tabular}

\begin{tabular}{|c|c|c|c|c|}
\hline Lereng & didalam gua & & $\begin{array}{l}\text { longsoran } \\
\text { minor }\end{array}$ & \\
\hline & $\begin{array}{c}\text { Sebagian } \\
\text { dilapisi oleh } \\
\text { lumut }\end{array}$ & & $\begin{array}{c}\text { Dominan } \\
\text { ditutup } \\
\text { vegetasi }\end{array}$ & \\
\hline $\begin{array}{c}\text { Kekuatan } \\
\text { Batuan }\end{array}$ & $\begin{array}{c}\text { Rendah - } \\
\text { Sedang }\end{array}$ & 4 & $\begin{array}{c}\text { Rendah - } \\
\text { Sedang }\end{array}$ & 4 \\
\hline RQD & $97 \%$ & 20 & $87 \%$ & 17 \\
\hline $\begin{array}{c}\text { Spasi Antar } \\
\text { Retakan }\end{array}$ & $25-150 \mathrm{~cm}$ & 15 & $50->1000 \mathrm{~cm}$ & 20 \\
\hline $\begin{array}{l}\text { Panjang } \\
\text { Retakan } \\
\end{array}$ & $3-9 m$ & 2 & $>10 \mathrm{~m}$ & 1 \\
\hline $\begin{array}{c}\text { Lebar } \\
\text { Retakan }\end{array}$ & $5-6 \mathrm{~cm}$ & 0 & $1-10 \mathrm{~cm}$ & 0 \\
\hline $\begin{array}{c}\text { Kekasaran } \\
\text { Bidang } \\
\text { Retakan } \\
\end{array}$ & Kasar & 5 & Kasar & 5 \\
\hline $\begin{array}{c}\text { Pengisi } \\
\text { Bidang } \\
\text { Retakan } \\
\end{array}$ & Lumut & 2 & Lumut & 2 \\
\hline $\begin{array}{c}\text { Pelapukan } \\
\text { Pada } \\
\text { Retakan } \\
\end{array}$ & $\begin{array}{l}\text { Segar- } \\
\text { Rendah }\end{array}$ & 5 & Rendah & 5 \\
\hline Airtanah & $\begin{array}{c}\text { Dinding } \\
\text { lembab dan } \\
\text { basah }\end{array}$ & 7 & $\begin{array}{c}\text { Dinding kering } \\
\text { sampai } \\
\text { lembab } \\
\end{array}$ & 10 \\
\hline Total Nilai & Fair Rock & 60 & Good Rock & 64 \\
\hline
\end{tabular}

Stasiun 1 (Tabel 1) berada di sebelah barat tebing, ditandai dengan adanya longsoran tepat disebelah air terjun buatan Hotel Samabe (Gambar 3). Lokasi ini dipergunakan untuk tempat istirahat para tamu. Dinding batuan sebagian terbuka dan sebagian lagi tertutup vegetasi. Dinding batuan yang terbuka banyak dijumpai rembesan airtanah yang keluar melalui celah retakan. Diperkirakan penyebab longsor adalah masuknya air dari bagian atas tebing ke air terjun buatan sehingga batuan disekitarnya mengalami pelapukan lebih intensif.

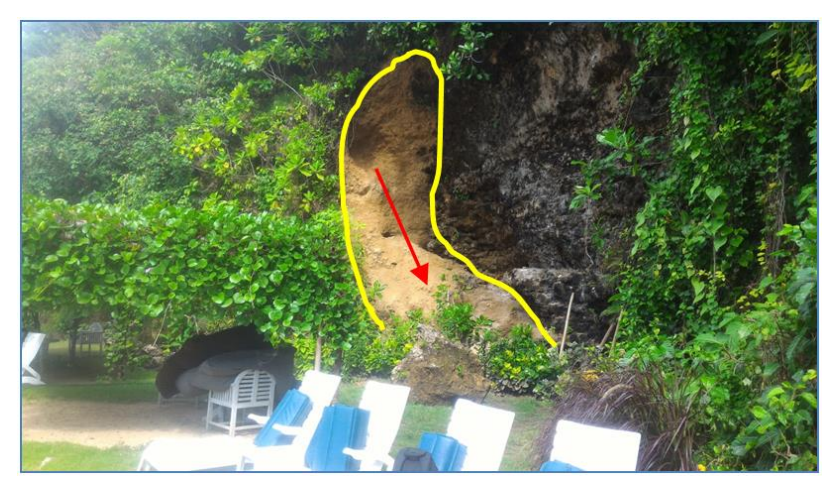

Gambar 3. Stasiun 1 Ditemukan Longsoran Minor di Dinding Tebing (Sumber Pribadi, 2017) 


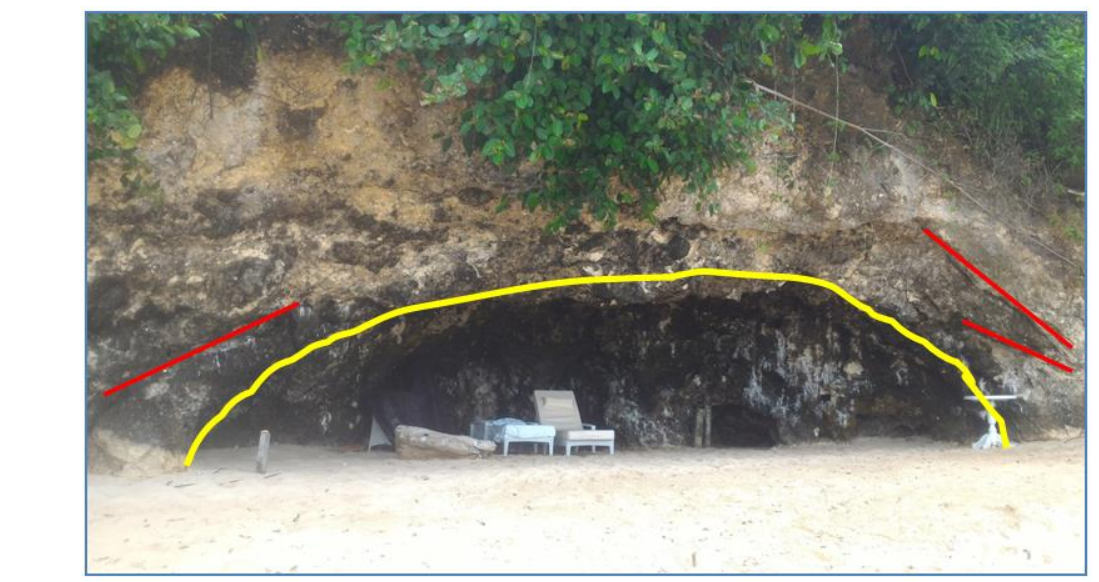

Gambar 4. Stasiun 2 Hasil Abrasi Air Laut (garis kuning); Kelurusan Patahan Geologi (garis merah)

Stasiun 2 (Tabel 1) merupakan gua alami di tepi pantai dengan dimensi lebar $8 \mathrm{~m}$ dengan tinggi $3 \mathrm{~m}$ dan kedalaman gua $5 \mathrm{~m}$ (Gambar 4). Lokasi ini dipergunakan untuk lokasi istirahat para tamu hotel menghadap ke laut. Dinding gua dilapisi tanaman lumut sampai mengisi kedalam retakan batuan. Kemungkinan didukung oleh rembesan airtanah atau air laut disaat pasang.

Stasiun 3 (Tabel 2) berlokasi di tepi pantai berupa morfologi gua dengan dimensi yang cukup besar dengan lebar gua sekitar $17 \mathrm{~m}$ dan tinggi gua sekitar $8 \mathrm{~m}$. Lokasi ini digunakan sebagai tempat makan malam bagi para tamu hotel (Gambar 5). Dinding gua dilapisi oleh tanaman lumut, kemungkinan didukung oleh airtanah yang merembes sehingga dinding menjadi lembab. Dimensi retakan didalam gua cukup besar dan sebagian area berpotensi runtuh.
Stasiun 4 (Tabel 2) berada di sebelah timur lereng Hotel Samabe di tepi pantai. Merupakan lokasi rencana elevator dari gereja ke tepi pantai. Pada bagian atas tebing telah terjadi jatuhan batuan akibat adanya pelapukan pada batuan. Tinggi tebing diperkirakan mencapai $70 \mathrm{~m}-80 \mathrm{~m}$ dari permukaan laut. Sebagain besar tebing tertutup oleh vegetasi dan tanaman lumut sehingga nampak berwarna kecoklatan.

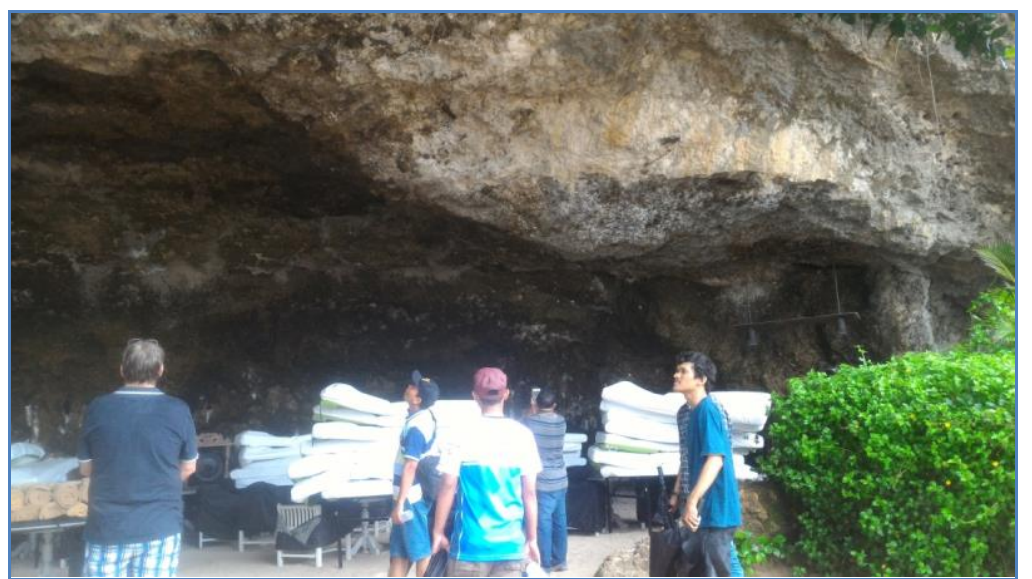

Gambar 5. Stasiun 3 Gua Alami Sebagai Ruang Makan Tamu (Sumber Pribadi, 2017) 


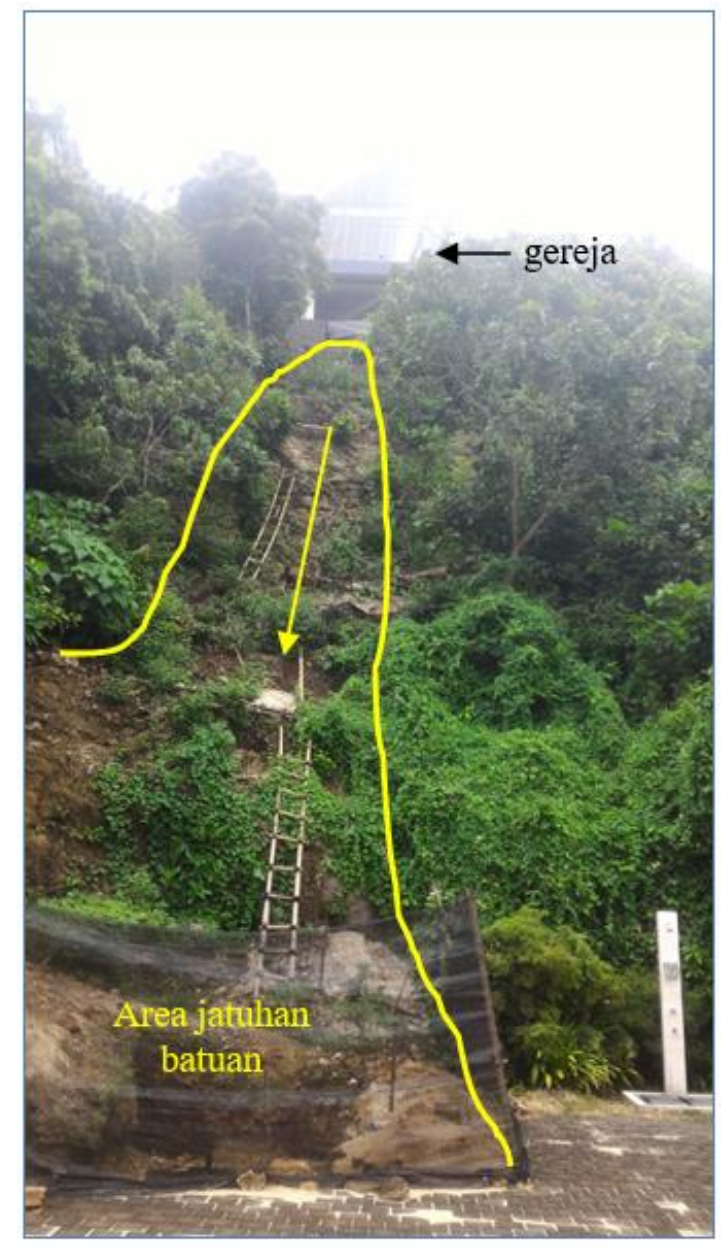

Gambar 6. Stasiun 4 Tebing Terjal Dibawah Gereja (Sumber Pribadi, 2017)

Kelas lereng ditentukan melalui nilai RMR yang dianalisa dari empat stasiun pengamatan. Nilai ini kemudian dimasukkan kedalam klasifikasi Kelas Lereng oleh (Bieniawski, 1989) serta penangannya sebagaimana Tabel 3. Berdasarkan pengaruh dimensi retakan yang ada dan kondisi batuan, Kelas Fair Rock memiliki total nilai RMR: $49-60$. Kelas ini meliputi Stasiun 1, 2 dan 3.

Tabel 3. Penanganan Lereng Berdasarkan Kelas Lereng

\begin{tabular}{|c|c|c|c|}
\hline $\begin{array}{l}\text { Kelas } \\
\text { Lereng }\end{array}$ & Stasiun & $\begin{array}{c}\text { Penanganan } \\
\text { (Bieniawski, 1989) } \\
\text { Rock Bolts (diameter } \\
20 \mathrm{~mm} \text { dan grouting } \\
\text { penuh) }\end{array}$ & $\begin{array}{c}\text { Penanganan } \\
\text { (Bieniawski, } \\
\text { 1989) } \\
\text { Shotcrete }\end{array}$ \\
\hline $\begin{array}{l}\text { Fair } \\
\text { Rock } \\
\text { (RMR: } \\
49- \\
60)\end{array}$ & $\begin{array}{c}1,2 \\
\text { dan } 3\end{array}$ & $\begin{array}{l}\text { Bolts sistematis } \\
\text { sepanjang } 4 \mathrm{~m} \text { dengan } \\
\text { spasi } 1,5-2 \mathrm{~m} \text { pada } \\
\text { bagian atas tebing dan } \\
\text { dinding. Ditambah } \\
\text { wire mesh pada }\end{array}$ & $\begin{array}{c}5-10 \mathrm{~cm} \text { di } \\
\text { bagian atas } \\
\text { tebing dan } 3 \mathrm{~cm} \\
\text { di dinding tebing }\end{array}$ \\
\hline
\end{tabular}

\begin{tabular}{ccc}
\hline \multicolumn{3}{c}{ bagian atas tebing } \\
\hline Good & Bolts sepanjang $3 \mathrm{~m}$ & $5 \mathrm{~cm}$ dibagian \\
Rock & pada bagian yang & atas lereng jika \\
(RMR: & beresiko runtuh. & dibutuhkan \\
$64)$ & Dengan spasi $2,5 \mathrm{~m}$ & \\
& dan wire mesh jika & \\
& diperlukan. & \\
\hline
\end{tabular}

\section{PENUTUP}

\section{Simpulan dan Saran}

Berdasarkan metode Rock Mass Rating di Hotel Samabe kategori batuan pada tebing di bawahnya termasuk dalam kategori fair rock dan good rock. Namun masih diperlukan penanganan khusus untuk lokasi yang rawan longsong minor dengan memasang rockbolts dan shorcrete berdasarkan ketentuan yang berlaku. Bangunan Hotel Samabe berada pada lahan dengan kondisi baik dengan metode penanganan tertentu.

\section{DAFTAR PUSTAKA}

Bieniawski, Z. (1989), Engineering Rock Mass Classifications: A Complete Manual for Engineers And Geologists In Mining, Civil, And Petroleum Engineering,

Pangular, D. (1985), Petunjuk Penyelidikan \& Penanggulangan Gerakan Tanah, Pusat Penelitian dan Pengembangan Pengairan, BALITBANG Departemen Pekerjaan Umum, 233.

Prengki, I. dan Heriyadi, B. (2018), "Analisis Beban Runtuh Dan Evaluasi Lubang Bukaan Berdasarkan Metode Rock Mass Rating Dan QSystem Pada Tambang Bawah Tanah CV. Bara Mitra Kencana, Kota Sawahlunto, Sumatera Barat", Bina Tambang, Vol.3, No.4, hal. 17291739. Diambil 29 Juli 2019 dari: http://ejournal.unp.ac.id/index.php/mining/arti cle/view/102293

Rajagukguk, O.C.P., Turangan, A.E. dan Monintja, S. (2014), "Analisis Kestabilan Lereng dengan Metode Bishop (Studi Kasus: Kawasan Citraland Sta.1000m)", Jurnal Sipil Statik, Vol.2, No.3. Diambil dari https://ejournal.unsrat.ac.id/index.php/jss/artic le/view/4762. 
Syaeful, H. dan Kamajati, D. (2017), "Analisis Karakteristik Massa Batuan di Sektor Lemajung, Kalan, Kalimantan Barat", Eksplorium, Vol.36, hal.17.

http://doi.org/10.17146/eksplorium.2015.36.1. 2768.

Zakaria, Z. (2011), "Analisis Kestabilan Lereng", hal. 43, Laboratorium Geologi Fakultas Teknik Geologi Universitas Padjajaran. Bandung,

Zakaria, Z., Muslim, D. dan Sophian, I. (2012), "Koreksi SMR pada Desain Lereng Tambang Terbuka Batubara pada Formasi Balikpapan \& Formasi Kampungbaru, Sangasanga, Kalimantan Timur (SMR Correction on Coal Openpit Slope Design Of Balikpapan \& Kampungbaru Formation, Sangasanga, Kalimantan Timur)", Buletin Sumber Daya Geologi, Vol.7, hal. 147-157. Diambil 29 Juli 2019 dari: http://buletinsdg.geologi.esdm.go.id/index.php /bsdg/article/view/115 